\title{
Definição Volumétrica a partir de um Sistema Generativo Evolutivo
}

\author{
Volumetric Definition from an Evolutionary Generative System
}

\author{
> Jarryer Andrade De Martino \\ UNICAMP, Brasil \\ jarryer_martino@hotmail.com
}

\author{
> Gabriela Celani \\ UNICAMP, Brasil \\ celani@fec.unicamp.br
}

\begin{abstract}
The objective of this paper is to present the volumetric modeling of a building through an evolutionary generative system, using weather information site. The methodology explored three experiments with two different approaches, one partially and one fully parameterized, obtaining results that directed the modeling process. The paper makes a brief theoretical introduction to the bioclimatic architecture, the description of the method used and the analysis of results.
\end{abstract}

Keywords: Evolutionary algorithms; Generative system; Optimization; Creative process; Insolation

\section{Introdução}

A verticalização na arquitetura vai além de um processo de adensamento; as torres assumem cada vez mais um valor simbólico da potencialidade do Homem e da sua cultura; são verdadeiros monumentos à ostentaçáo tecnológica, servindo de ícones entre naçôes que competem entre si para ter o título de possuírem o maior edifício do mundo. Segundo Arantes (2012), quando em 1996 as Petronas Towers em Kuala Lumpur foram concluídas, a mídia americana foi uma das primeiras a noticiar o evento, pois a partir daquele momento, o edifício mais alto do mundo era oriental e encontrava-se fora dos EUA. Isso reforça a ideia de que o edifício alto assume o status de um marco nas grandes viradas históricas, dando indícios da rotaçâo do capital, refletindo um vínculo intrínseco entre metrópole e a abstração da economia monetária. É importante destacar que a altura de um arranha-céu não se resume apenas à inserçáo de mais pavimentos e a sua capacidade de adensamento, mas principalmente na necessidade do desenvolvimento de tecnologias estruturais, superaçáo de forças naturais, infraestrutura adequadas para suprir todos os efeitos e necessidades dessa verticalização, caracterizando o potencial econômico e tecnológico do empreendedor.

O arranha-céu nasce como resultado de uma ambição especulativa, uma cidade dentro de outra, implicando em sobreposiçóes de funçóes e assumindo uma escala que rompe com a relação direta com o espaço urbano, desvinculando a relação entre a superfície que o envolve e o seu conteúdo, fazendo deste um espaço interior potencialmente infinito e independente (Koolhaas \& Bottman, 2008). Sob essa ótica, o edifício passa a ser assumido como uma pele que intermedia o espaço urbano e o seu interior, criando condições ambientais favoráveis para a sua ocupação. A partir desse contexto e diante das atuais discussóes sobre crise ambiental, questóes relacionadas à sustentabilidade tornam-se frequentes. Certificaçôes como LEED (Leadership in Energy and Environmental Design) e BREEAM (Building Research Establishment Environmental Assessment Methodology) conduzem à regulamentaçáo e ao direcionamento do desenvolvimento de projetos de edifícios sustentáveis. Embora, a princípio, essa preocupaçáo tenha como objetivo amenizar o impacto ambiental, é possível perceber que a incorporação das questôes climáticas no partido arquitetônico já está se tornando parte do processo de projeto.

Segundo Yeang (1994), o processo de projeto arquitetônico deixa de ser uma mera arte extravagante, assumindo o potencial de uma ciência confiável, ao assumir uma metodologia embasada na pesquisa, desenvolvimento e design. Dessa forma, cada projeto procura expandir os limites dessa pesquisa, buscando sempre caminhar em direção a uma arquitetura ecologicamente sensível. Para isso, ele define quatro justificativas fundamentais para esse tipo de projeto, (1) a reduçáo do consumo de energia durante a fase de operaçáo do edifício, (2) a possibilidade de oferecer bem estar ao usuário, permitindo usufruir do clima externo local, (3) a questão ecológica, explorando os dados meteorológicos do local a fim de se obter a eficiência e menos dependência dos combustíveis fósseis, e (4) a possibilidade de estabelecer o regionalismo arquitetônico, caracterizada pela adaptação climática regional, assumindo maior ajuste ao seu contexto geográfico. 
Diante desse contexto é possível verificar que o projetar assume um novo status, fazendo da informação a matéria prima a ser gerenciada, manipulada, avaliada e tratada, apresentando um peso considerável durante todo o processo de projeto, que assume um alto nível de complexidade. Uma nova demanda passou a existir, e os projetos passaram a ser avaliados também pela sua eficiência energética, exigindo a obtençáo de soluçóes que possam atender de forma satisfatória e simultânea as diferentes variáveis envolvidas no processo de projeto, e que na maioria das vezes são conflitantes e contraditórios. Um exemplo é o atendimento simultâneo de parâmetros como maior ventilação e iluminação natural com o menor ganho térmico. Dessa forma, o avanço tecnológico das ferramentas digitais possibilitou aos arquitetos definirem métodos projetuais com um caráter muito particular, permitindo a criação dos seus próprios sistemas e ferramentas capazes de gerar, simular e controlar o complexo número de informaçóes sobre um determinado problema, envolvendo assim um alto nível tecnológico (Tierney, 2007, p. 99). Atualmente é possível encontrar métodos de outras áreas, como da computação evolutiva, inseridos nas ferramentas digitais, potencializando o processo de desenvolvimento projetual.

Assim, este artigo propóe a utilização de um método originário da computação evolutiva, os algoritmos evolutivos (AE), como uma ferramenta capaz de auxiliar no processo de modelagem volumétrica de um edifício, realizando uma negociação entre a sua definição formal e a distribuição da insolação sobre a sua superfície, conforme as condiçóes climáticas de um determinado local. Para isso, foi adotado um sistema generativo, ou seja, um sistema definido a partir do entendimento do problema e da sua decomposição, sendo realizada a identificação das variáveis, dos componentes e das suas relaçóes, de maneira a permitir a estruturação de um sistema capaz de gerar automaticamente diversos resultados. A este sistema foram associados os algoritmos evolutivos (AE), compondo um mecanismo de busca e avaliação dos resultados. Esses algoritmos são responsáveis pela combinação entre as diferentes soluções obtidas no sistema generativo, promovendo a criação de novas soluçóes e aplicando em algumas delas sutis transformaçôes (mutação) a fim de se obter certo grau de diversidade. Após esse processo, as soluções são avaliadas conforme o grau de satisfação aos critérios que definem as características desejadas no projeto, sendo atribuído um valor (fitness) responsável pela classificação de cada solução (também denominado como indivíduos). Somente os melhores classificados serão selecionados para uma nova combinação, sendo repetido esse processo até a obtenção dos indivíduos, ou soluçóes, que melhor satisfaçam simultaneamente todos os critérios. A adoção deste sistema generativo evolutivo pode ser utilizada como um exemplo do potencial tecnológico agregado ao processo de projeto, viabilizado através das atuais tecnologias digitais.

\section{Metodologia}

O sistema generativo facilitou a adoção de uma metodologia com caráter experimental (Groat \& Wang, 2013), pois a partir de diferentes configurações do sistema foi possível realizar três experimentos. O experimento apresentou como objetivo a definição volumétrica de um edifício a fim de obter a distribuição mais homogênea possível da sua taxa de insolaçáo sobre todas as suas superfícies no período entre $8 \mathrm{~h}$ e $18 \mathrm{~h}$, na cidade de Sáo Paulo (Brasil), além de buscar a maximização desse valor. Duas abordagens foram definidas para a concepção da volumetria do edifício, uma parcialmente parametrizada (com variação apenas na sua volumetria), e a segunda totalmente parametrizada (permitindo variaçóes na implantação e volumetria do edifício). Os dois primeiros experimentos (EX1 e EX2) foram fundamentados na abordagem parcialmente parametrizada, se diferenciando nos critérios de avaliação e seleção das soluçóes criadas pelos AE. Os critérios que favoreceram a obtenção dos melhores resultados foram incorporados no terceiro experimento (EX3), mas sob a fundamentaçáo da segunda abordagem.

A implementação do projeto ocorreu através do plugin Grasshopper (editor gráfico de algoritmos) para o software Rhinoceros da McNeel (programa de modelagem geométrica tridimensional baseado na tecnologia NURBS), utilizando o componente Galapagos e os recursos do Geco, (add-on responsável pela integração com o programa Ecotect da Autodesk). O Geco exporta a modelagem tridimensional composta por uma superfície triangulada para o Ecotect, onde será realizada a simulação da insolação sobre o edifício, considerando os dados climáticos do local previamente definido pelo projetista (cidade de São Paulo). As informaçóes obtidas na simulação, a carga energética atribuída a cada triangulação da superfície, retornam para o Grasshopper, sendo avaliado pelos critérios dos AE. Para isso, foi criado um modelo paramétrico tridimensional do edifício (Figura 1), composto por três polígonos sobrepostos, cada um contendo três lados e circunscritos em uma circunferência de $16 \mathrm{~m}$ de raio. O primeiro foi posicionado na base (definindo a implantação do edifício), o segundo na porção central (a $24 \mathrm{~m}$ de altura do primeiro), e o terceiro no topo do volume (a $48 \mathrm{~m}$ de altura com relação à base). O EX1 e o EX2 não apresentaram variaçóes no polígono da base, definindo assim, uma implantação fixa durante todo o processo de execução dos $\mathrm{AE}$, a variação da rotação ocorreu apenas no EX3. O polígono intermediário e o do topo foram configurados para variar nos três experimentos, sofrendo transformaçóes no tamanho (através de um fator de escala entre 0,5 e 1,5) e no seu deslocamento através da realizaçáo de rotaçóes (variando entre $0^{\circ}$ e $120^{\circ}$, com valores pares para o polígono intermediário e ímpares para o do topo), permitindo a torsão da volumetria e a provável adaptação ao recebimento da luz solar, as ambas variáveis foram controladas automaticamente pelos AE.

A configuração inicial para o volume do edifício, utilizada em todos os experimentos, apresentou uma rotação de $120^{\circ}$ e o fator de escala igual a 0,5 para o polígono intermediário, para o do topo foi definida a rotação de $121^{\circ}$ e o fator de escala de 0,6 , gerando uma torção na volumetria. Os AE foram configurados para obter a maximização do fitness (valor máximo para a taxa de insolação sobre as superfícies do edifício medida $\mathrm{em} \mathrm{Wh} / \mathrm{m}^{2}$ ), a execuçâo dos $\mathrm{AE}$ até obter uma estagnação de 50 geraçóes sucessivas ou a quantidade de 50 geraçóes (independente da estagnação), a população de 20 indivíduos por geração, dos quais 5\% foram mantidos de uma geraçáo para outra, e a definiçáo do cruzamento entre os indivíduos com grau de semelhança de 75\% (mantendo o grau de 
Modelo paramétrico

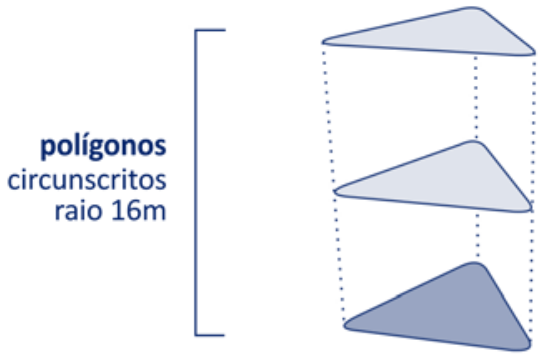

rotação

intervalos ímpares

$1^{\circ}$ a $121^{\circ}$

intervalos pares

$0^{\circ}$ a $120^{\circ}$

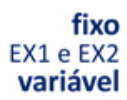

variável

EX3

escala

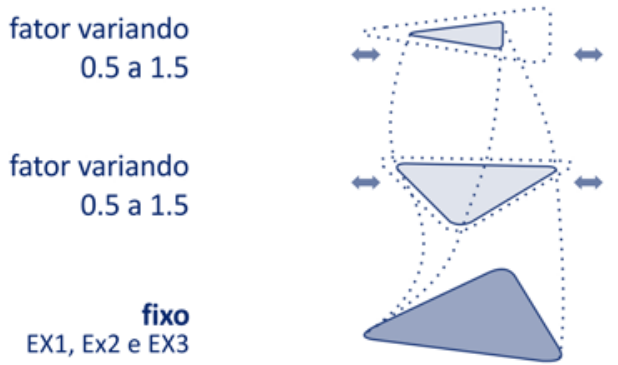

Figura l: Configuração inicial do volume do edifício. Elaborado pelos autores.

familiaridade entre os indivíduos com o objetivo de se preservar as características favoráveis entre as geraçōes).

O código que representa o projeto foi estruturado em três blocos, o primeiro constituído por elementos construtores da forma e as suas relaçōes paramétricas, o segundo responsável pelos AE e os critérios para a avaliaçấo das soluçôes, e o terceiro relacionado à simulaçãao da insolação.

\section{Resultados}

A associação entre as diferentes variáveis que constituem o modelo paramétrico, e que alimentaram os $\mathrm{AE}$, contribuiu para a definiçáo de um sistema parametrizado que gerou um amplo espaço de soluçóes. Foram geradas em cada experimento aproximadamente 2550 possibilidades volumétricas para o edifício ( 50 geraçôes com 50 indivíduos cada, mais os 50 indivíduos a mais na geração inicial). A análise dos resultados obtidos pelo sistema generativo evolutivo adotou o mesmo critério utilizado nos $\mathrm{AE}$, ou seja, a soluçáo que apresentasse a distribuiçáo da insolaçáo de forma mais homogênea
Geração 1

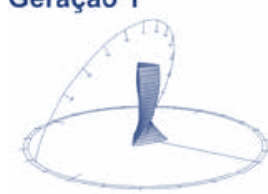

Geração 10

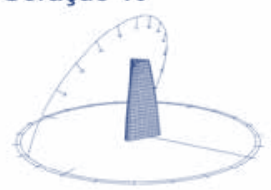

Geração 30

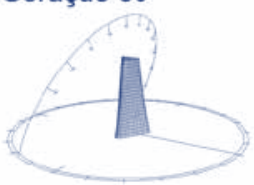

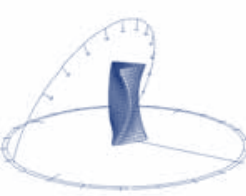

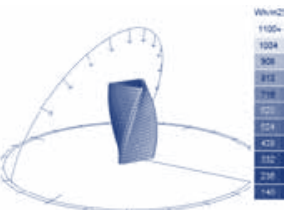

Geraçāo 20
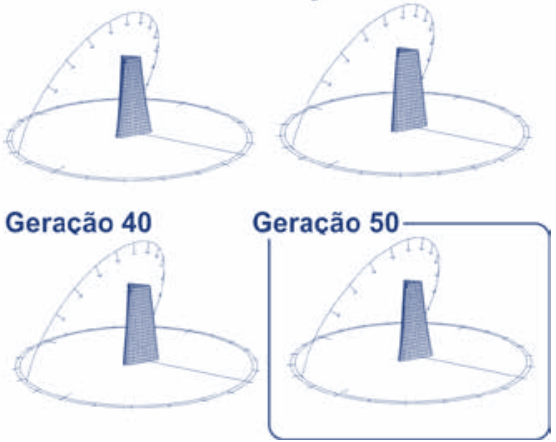

Figura 2: Comparação entre os melhores indivíduos obtidos cada 10 geraçóes. Elaborado pelos autores.

nas três superfícies do edifício, considerando também a sua maximização. Essa avaliação pode ser realizada visualmente, utilizando a escala cromática gerada pelo Ecotect, que associa a cada cor um valor de carga energética.

No EX1 foi verificado que mesmo diante da possibilidade de torção do edifício, isso não contribuiu para a geraçẫo de uma forma que possibilitasse uma melhor distribuição da insolação nas suas superfícies (Figura 2). Desmistificando a ideia inicial do projetista de que a torçẫo favoreceria a insolação sobre as superfícies.

Cada superfície assumiu um valor máximo específico e contrastante, que pode ter ocorrido em funçáo da má formulação da restrição, não sendo estabelecida qualquer relaçấo entre o valor de máximo e mínimo para a taxa de insolação. A restrição criada para este experimento ficou limitada em selecionar as soluçóes com o maior valor para a taxa mínima, sem definir qualquer outra referência com a taxa máxima. Para corrigir esse problema, a restrição foi reformulada e estruturada em três partes, a busca pela maximização do valor mínimo e do valor máximo para a taxa de incidência da insolação, e a definição de uma relação de

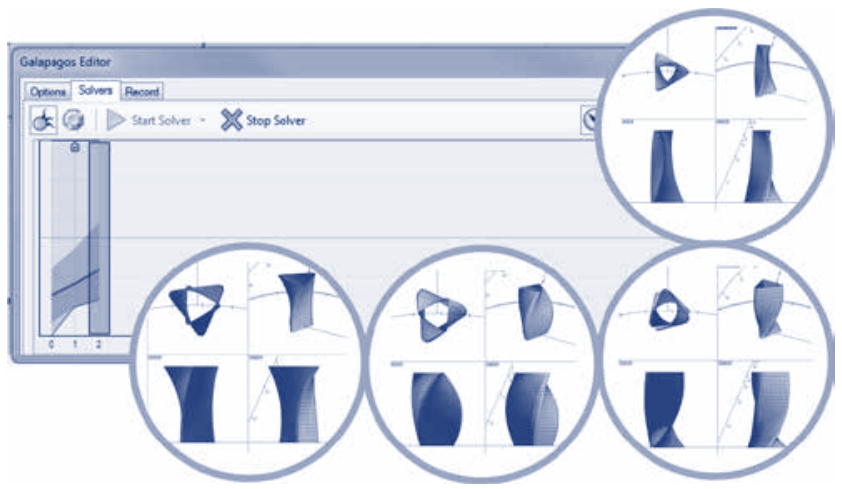

Figura 3: Exploração formal nas 10 primeiras geraçóes do EX1 e EX2. Elaborado pelos autores. 


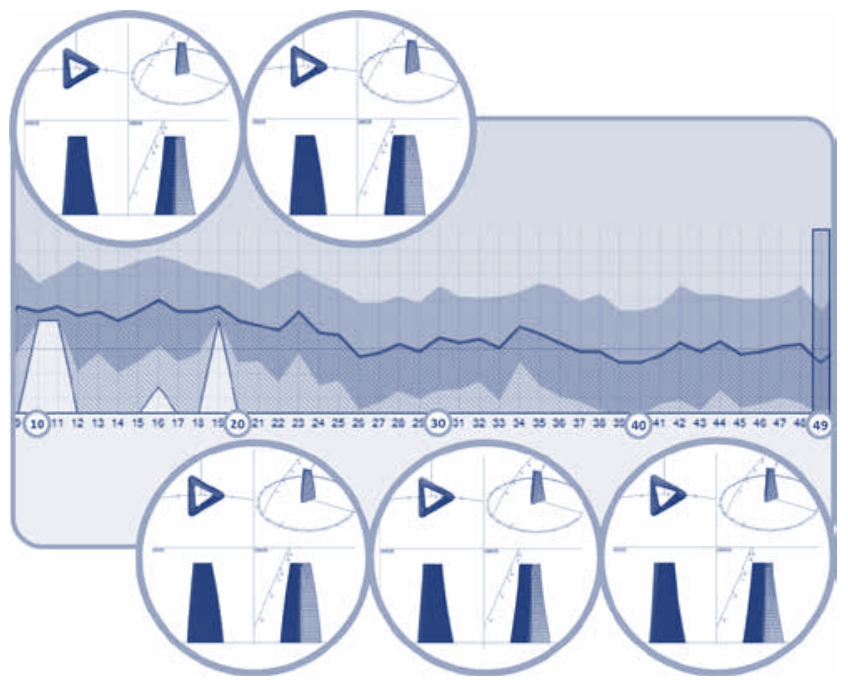

Figura 4: Variaçôes entre a décima e a última geração do EX1 e EX2, resultados praticamente iguais com pequenos ajustes. Elaborado pelos autores.

similaridade entre esses valores, permitindo uma variação de $20 \%$ (para mais ou para menos).

Os resultados obtidos no EX2 foram praticamente os mesmos do EX1, apresentando o mesmo comportamento evolutivo em ambos os casos. A exploração formal ocorreu de forma mais diversificada nas dez primeiras geraçôes, (Figura 3), apresentando posteriormente soluçóes muito parecidas entre si, convergindo rapidamente para uma solução e sofrendo apenas alguns ajustes (Figura 4).

Acredita-se que o resultado semelhante entre os dois experimentos ocorreu pela impossibilidade do algoritmo de encontrar soluçôes que tivessem similaridade desejada entre os valores de máximo e mínimo. Isso ocorreu devido presença constante, em ambos os experimentos, de regióes com o máximo de sombreamento e áreas com a máxima insolaçấo, criando valores muito distantes entre o mínimo e o máximo e impossível a obtenção de similaridade. Isso revela que as variáveis definidas no modelo paramétrico náo foram suficientes para obter uma combinação favorável às soluçóes que se enquadram no critério de avaliação, não existindo indivíduos que atendesse as condiçóes desejadas.

Essa dificuldade pode ser amenizada com a adoçáo de mais variáveis ao modelo, contribuindo para ampliar o espaço de soluçóes e gerando maior número de possibilidades formais. Dessa forma, no terceiro experimento foi acrescentada a rotaçáo da base do edifício às outras duas variáveis, permitindo aos $\mathrm{AE}$ girar o volume em um todo, e náo apenas torcendo a sua parte central e o topo, contribuindo para encontrar a melhor implantação, além da modelagem do volume. Dessa forma, o terceiro experimento assumiu como variáveis a rotação dos três polígonos do volume (base, centro e topo) e a possibilidade de redefiniçáo da escala para os polígonos do centro e do topo. A outra alteração realizada foi a redefiniçáa das restriçóes, que passou a considerar apenas a maximização do valor mínimo da taxa de insolação e o grau de semelhança entre o valor mínimo e o máximo. Pois assim, os $\mathrm{AE}$ poderiam achar soluçóes com valores máximos menores do que a

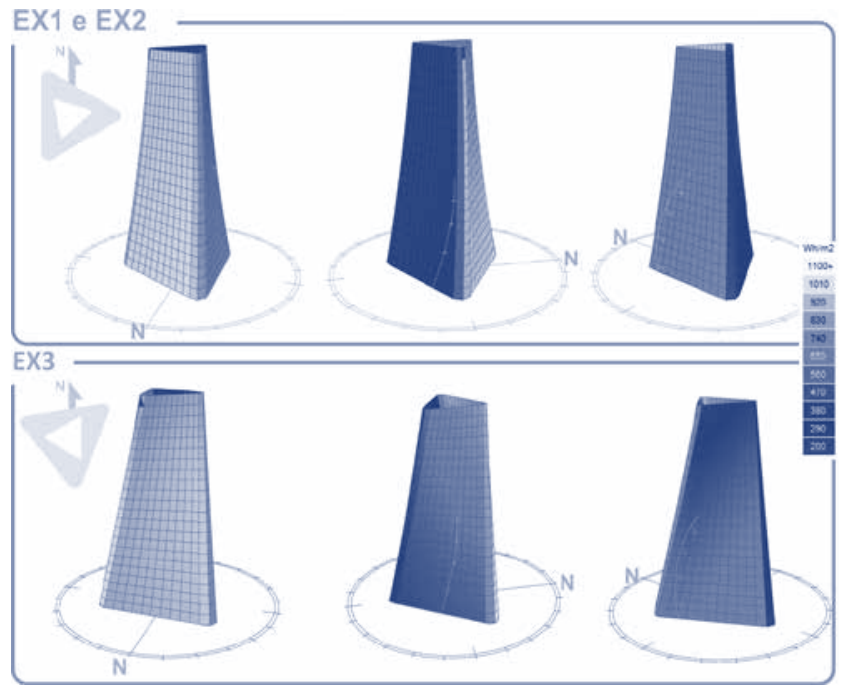

Figura 5: Comparação entre os resultados obtidos nos três experimentos. Elaborado pelos autores.

dos outros experimentos, diminuindo a sua diferença com relação ao valor mínimo, facilitando a obtenção da similaridade e tornando o critério de avaliação mais flexível, priorizando a satisfação da restrição do grau de similaridade.

Ao comparar os EX1 e EX2 com o EX3 é possível verificar neste último um contraste menor entre as três superfícies do edifício, demonstrando a distribuição mais homogênea da insolação. Isso torna evidente que a possibilidade de rotação do polígono da base favoreceu a obtençáo dessa solução, assim como a redefinição da restriçâo. Embora ainda existam áreas de sombreamento no EX3, elas correspondem a regióes menores e distribuídas em diferentes superfícies da volumetria do edifício, além de apresentarem um índice maior de carga energética de $300 \mathrm{Wh} / \mathrm{m}^{2}$, contra os 200 $\mathrm{Wh} / \mathrm{m}^{2}$ dos experimentos EX1 e EX2. É interessante perceber que o resultado formal da volumetria é muito semelhante aos obtidos no EX1 e no EX2, ficando a diferença apenas pela sutil rotaçáo no topo e o reposicionamento da implantação do edifício, sofrendo uma rotação com relação ao Norte. Pequenos ajustes que foram suficientes para oferecer um resultado mais eficiente quanto à distribuição mais homogênea da insolação nas superfícies do edifício e à maximizaçâo da carga energética mesmo nas regiôes mais sombreadas.

\section{Conclusão}

A utilizaçáo das tecnologias digitais potencializou o processo de projeto, uma vez que, os recursos computacionais passaram a oferecer cada vez mais condiçóes para a obtenção de dados informacionais. Atualmente vivemos uma era onde a tecnologia é manipulada e moldada às nossas necessidades, sendo criadas novas situaçóes que até então não existiam ou não tinham demanda. O distanciamento entre o usuário e os meios digitais está cada vez mais diluído, e passaram a estabelecer uma relação de parceria, onde cada um assume ações específicas diante do processo (Terzidis, 2009). A fronteira que era bem definida diluiu-se, dando origem a um espaço único, integrado e potencializado, possibilitando ao projetista navegar 
fluidamente entre os diferentes territórios disciplinares, implementando o pensamento algorítmico, a computação, a adoção da análise do desempenho como critério no processo de design, a incorporação de conceitos da engenharia como a otimização (não apenas como estratégia orçamental, mas também nas estratégias formais e organizacionais), permitindo descobrir e criar novas técnicas (Kolarevic, 2009). Além disso, o impacto das novas técnicas digitais extrapola o processo projetual, ganhando campo na documentação, fabricação e montagem dos edifícios, propiciando a emergência de uma arquitetura que reflete a era digital, apresentando alto nível de complexidade, capacitando uma maior sensibilidade, e respondendo as exigências dos aspectos contextuais como o lugar, o programa e a intenção expressiva (Oxman, 2006).

Nesse contexto, é possível observar e refletir como o sistema generativo evolutivo aplicado neste experimento potencializou o processo de projeto na fase de concepção, adotando a otimização como um critério para a exploração formal do edifício, ampliando o uso deste conceito. A presença de ferramentas nos meios digitais que facilita a incorporação de conhecimentos de outras áreas no processo de projeto, como os $\mathrm{AE}$, contribui para o desenvolvimento de metodologias que potencializam o processo projetual, permitindo ao projetista criar diferentes abordagens e maior aproximação com a sua intenção e o contexto geográfico. Embora este artigo tenha apresentado apenas a metodologia de implementação e utilizaçáo dos AE para a definição volumétrica, a partir da insolação, é possível perceber as possibilidades que podem se desdobrar a partir desse experimento, trazendo benefícios que irão agregar ao edifício não apenas uma qualidade projetual, mas gerando possibilidades para o desenvolvimento de projetos complementares que possam contribuir para a reduçáo de consumo de energia, ou a obtenção de recursos energéticos naturais, entre outras questóes abordadas pelas certificaçóes e que poderiam ser viabilizadas pelos recursos digitais.

\section{Agradecimentos}

Os autores agradecem à FAPESP pela concessão da bolsa de doutorado de Jarryer A. Martino, processo 2012/18112-7.

\section{Referências}

Arantes, O. (2012). Chai-na. São Paulo: Edusp.

Kolarevic, B. (2009). Towards Integrative design. International Journal of Architectural Computing 7 (3), 335-344.

Koolhaas, R.; bottman, D. (2008). Nova York delirante: um manifesto retroativo para Manhattan. São Paulo: Cosac Naify.

Groat, L.; Wang, D. (2013). Architectural research Methods. 2ed. New York: Wiley.

Oxman, R. (2006). Theory and design in the first digital age. Design Studies 27 (3), 229-265.

Terzidis, K. (2009). Algorithmic architecture. Oxford: Elsevier. Yeang, Y. (1994). Bioclimatic skyscrapers / Hamzah \& Yeang T.R. Hamzah \& Yeang Sdn. Bhd; with essays by Alan Balfour. 2ed. London: Ellipsis. 